\title{
Influência das Condições de Processamento nas Propriedades Mecânicas de Compósitos de Polipropileno com Fibras de Vidro.
}

\author{
Paulo Edson Lopes e José Alexandrino de Sousa
}

Resumo: A eficiência de reforçamento de termoplásticos com fibras de vidro (FV) curtas depende da preservação do comprimento médio da $\mathrm{FV}\left(\mathrm{L}_{\mathrm{n}}\right)$ durante o processamento e da otimização das interações na interface fibra-polímero. Investigamos neste trabalho, a influência das variáveis materiais e de processamento (viscosidade, temperatura, rotação e configuração da rosca) numa extrusora dupla-rosca e das interações interfaciais com agente de acoplagem (aminosilano) e compatibilizante interfacial (PP-g-MAH) nas propriedades mecânicas de compósitos de polipropileno (PP) com $30 \%$ em peso de FV. As variáveis que contribuíram para a preservação do $\mathrm{L}_{\mathrm{n}}$ da FV na extrusora foram aquelas que permitiram a menor viscosidade da matriz na zona de mistura da FV na extrusora, enquanto aumento na rotação e perfil de cisalhamento mais intenso da rosca, apesar de reduzirem o $\mathrm{L}_{\mathrm{n}}$ da FV, contribuíram para maior molhamento/adesão interfacial da FV pela matriz, resultando em superior resistência à tração $\left(\sigma_{\text {máx }}\right)$ e inferior resistência ao impacto Izod (RI) dos compósitos. $\mathrm{O}$ uso de PP-g-MAH resultou em aumentos substanciais na $\sigma_{\text {máx }}$ e RI do compósito, em função do compatibilizante interfacial influir positivamente tanto na preservação do $\mathrm{L}_{\mathrm{n}}$ da $\mathrm{FV}$ como na melhoria da adesão interfacial fibra-polímero, confirmada por análise morfológica MEV de superfícies crio-fraturadas.

Palavras-chave: Compósitos, polipropileno, fibras de vidro, compostagem, extrusora dupla-rosca, propriedades mecânicas, interface/interfase, compatibilizante interfacial, PP-g-MAH.

\section{Introdução}

O uso de polipropileno (PP) com fibras de vidro (FV) é ainda hoje objeto de muita investigação científica e tecnológica, em função do grande atrativo deste compósito de baixo custo para aplicações de engenharia cada vez mais exigentes, como requeridas na indústria automobilística, onde os requisitos da relação custo/desempenho mecânico devem ser otimizados em função do entendimento das correlações processamento-estrutura-propriedades mecânicas de termoplásticos reforçados com fibras de vidro curtas (TPRFVc) ${ }^{[1-5]}$. Portanto, a grande maioria dos desenvolvimentos desta última década estão concentrados na melhoria das características materiais do compósito, isto é, a matriz polimérica, o reforço fibroso e a interface polímeroreforço, e no aprimoramento das técnicas de processamento na composição/compostagem e transformação de TPRFVc ${ }^{[6-11]}$. 


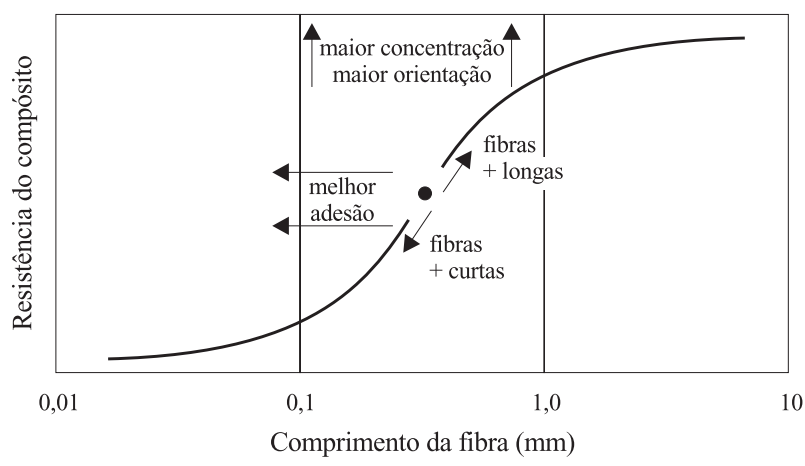

Figura 1. Principais fatores que afetam a resistência mecânica dos compósitos de termoplásticos reforçados com fibras de vidro curtas $(\mathrm{TPRFVc})^{[9]}$.

Os principais parâmetros materiais que influenciam em maior ou menor grau na eficiência de reforçamento de termoplásticos com FV curtas, estão resumidos na Figura 1, onde a resistência mecânica do compósito está relacionada ao comprimento da FV, e a outros fatores, tais como a orientação, concentração da FV e adesão interfacial polímero-reforço.

A resistência mecânica do compósito desloca ao longo da curva em "S" para maior ou menor valor em função do comprimento da FV, enquanto aumentos na concentração e no grau de orientação da FV desloca a curva verticalmente para cima. A curva em "S" é também deslocada horizontalmente à esquerda para menores comprimentos da FV com aumento da adesão interfacial fibra-polímero, conforme explicado a seguir.

Para um determinado grau de adesão interfacial alcançado no compósito, o comprimento médio $\left(\mathrm{L}_{\mathrm{n}}\right)$ da fibra no compósito deve ser maior que o seu comprimento mínimo crítico $\left(\mathrm{L}_{\mathrm{c}}\right)$, necessário para uma eficiente transferência de tensão da matriz para as fibras de reforço, segundo a equação de Kelly e Tyson descrita na literatura ${ }^{[12-15]}$ :

$$
\left(\mathrm{L}_{\mathrm{c}} / \mathrm{d}_{\mathrm{f}}\right)=\left(\sigma_{\mathrm{f}} / 2 \tau_{\mathrm{i}}\right)
$$

onde, $\sigma_{\mathrm{f}}$ é a resistência máxima da fibra e $\tau_{\mathrm{i}}$ é a resistência ao cisalhamento interfacial fibra-polímero ou a resistência ao cisalhamento da matriz, qualquer uma das duas sendo alcançada primeiro, e $\mathrm{d}_{\mathrm{f}}$ é o diâmetro da fibra. Pela equação 1, quanto maior for o valor de $\tau_{\mathrm{i}}$ obtido pelo aprimoramento da adesão interfacial, menor será o valor da razão de aspecto crítico $\left(\mathrm{L}_{\mathrm{c}} / \mathrm{d}_{\mathrm{f}}\right)$ da fibra necessário para um reforçamento eficiente do compósito, deslocando a curva em "S" da Figura 1 para valores menores de $\mathrm{L}_{\mathrm{n}}$ da fibra. Quando se obtém uma boa adesão interfacial em TPRFVc, somente valores de $\mathrm{L}_{\mathrm{n}}$ acima de cinco a dez vezes do seu comprimento crítico $\left(\mathrm{L}_{\mathrm{c}}\right)$ permitirão máxima eficiência de reforçamento, equivalente à resistência de termoplásticos reforçados com fibras contínuas ${ }^{[9,13,15,19]}$.

As condições de mistura necessárias para assegurar uma boa incorporação da FV curta na matriz polimérica durante o processo de compostagem em extrusoras, requerem a alimentação da FV num estágio avançado da extrusora, com o polímero devidamente fundido, e também suficiente trabalho de mistura dispersiva e distributiva visando promover debulhamento dos fios "rovings" picotados da FV em filamentos individuais, molhamento da sua superfície pelo polímero para assegurar boa adesão interfacial, e dispersão homogênea da FV na matriz, sem entretanto, levar à quebra excessiva no comprimento da $\mathrm{FV}^{[3-5,8,11]}$. Como as condições de processamento influenciam de forma oposta no molhamento/adesão interfacial da $\mathrm{FV}$ e na preservação do $\mathrm{L}_{\mathrm{n}}$ da $\mathrm{FV}$, tornase importante obter um balanço adequado entre estes dois fatores durante a fabricação do compósito.

Neste sentido, busca-se aumentar a eficiência de reforçamento do compósito através da otimização das variáveis materiais e de processamento na compostagem de TPRFVc por extrusão e no subsequente processo de moldagem por injeção em produtos acabados ${ }^{[2-11]}$, como também pela otimização da adesão interfacial polímeroreforço com tratamento superficial das fibras utilizando agentes de molhamento e de acoplagem interfacial (silanos, titanatos, etc.) e por adição de compatibilizantes interfaciais (PP-g-MAH) ${ }^{[18-24]}$.

Comercialmente, TPRFVc são normalmente compostos em extrusoras dupla-rosca com segmentos da rosca especialmente projetados para atender os acima mencionados requisitos de mistura na zona de malaxagem (kneading) da extrusora. Com respeito a preservação do comprimento da FV durante a compostagem, diversos pesquisadores ${ }^{[2-4,6-8,10-12,17]}$ têm constatado que a maior parte da quebra da FV ocorre num período relativamente curto, logo após a incorporação da fibra na zona de malaxagem da extrusora, até o ponto em que os filamentos individuais da FV são efetivamente molhados e encapsulados pela matriz polimérica. O grau de quebra da FV dependerá do perfil de cisalhamento imposto pela geometria dos segmentos de mistura da rosca na zona de malaxagem e também das características reológicas e de tensão superficial/ molhabilidade da matriz polimérica utilizada ${ }^{[2,3,6-8,11,17]}$. Com respeito a adesão interfacial fibra-polímero do compósito, deve-se assegurar no processo de compostagem suficiente trabalho de dispersão e de molhamento da FV pela matriz, para assim propiciar as 
possíveis interações interfaciais em função da afinidade natural do sistema polímero-reforço ou da afinidade introduzida através do tratamento superficial da FV com agentes de acoplagem e compatibilizantes interfaciais ${ }^{[18-24]}$. Entretanto, devido a complexidade inerente à correlação processamento-estrutura-propriedades mecânicas de TPRFVc, poucos trabalhos na literatura acima revisada analisaram conjuntamente a influência das variáveis de processamento na compostagem e das interações interfaciais polímero-reforço nas propriedades mecânicas de PP reforçado com FV.

Levando em consideração o acima exposto, investigamos neste trabalho a influência conjunta das variáveis de processamento numa extrusora de rosca-dupla (configuração e rotação da rosca e perfil de temperatura), da viscosidade da matriz polimérica e das interações interfaciais, utilizando um compatibilizante interfacial - polipropileno graftizado com anidrido maleico (PP-g$\mathrm{MAH})$, na eficiência de reforçamento de compósitos de PP com $30 \%$ em peso de FV tratada com aminosilano (PP/FV30). A eficiência de reforçamento foi investigada através de ensaios mecânicos de resistência à tração e impacto pendular Izod, enquanto através da análise morfológica por microscopia eletrônica de varredura (MEV) de superfícies crio-fraturadas, buscou-se qualificar o grau das interações interfaciais obtidas nos compósitos de $\mathrm{PP} / \mathrm{FV}$.

\section{Experimental}

Os materiais empregados incluíram dois tipos de PP homopolímero - Prolen KM6100 (MFI=3,53 $\mathrm{g} / 10 \mathrm{~min})$ e VM6100K (MFI=19,6 g/10min) da Polibrasil (denominados neste trabalho como PP3,5 e PP20 respectivamente), devidamente termoestabilizados pela adição de antioxidantes/estabilizantes térmicos da Ciba-Geigy - 0,2 \% Irganox 1010 (fenol estericamente impedido) e 0,4\% Irgafos 168 (fosfito). A escolha destes dois tipos de PP foi baseada nas conclusões apresentadas na literatura acima revisada ${ }^{[11,17]}$, onde buscou-se estabelecer a influência da viscosidade da matriz de PP no molhamento e encapsulamento da FV para preservação do seu comprimento e na otimização da adesão interfacial do compósito durante o processo de compostagem. As fibras de vidro curtas utilizadas foram do tipo $\mathrm{P} 337 \mathrm{da}$ Vetrotex $\left(\mathrm{d}_{\mathrm{f}}=13 \mu \mathrm{m}\right.$ e $\mathrm{L}_{\mathrm{f}}=4,5 \mathrm{~mm}$ ) com ensimagem (sizing) que incluiu um tipo de aminosilano. O compatibilizante interfacial reativo empregado foi o PP-g-MAH - "Polybond 3150" (MFI=50,0 g/10min) da Uniroyal.

A preparação dos compósitos de $\mathrm{PP} / \mathrm{FV}$ foi efetuada numa extrusora de rosca dupla corotacional, ZSK-30 da Werner \& Pfleiderer com L/D de 35, à uma taxa de produção (vazão) constante de $15 \mathrm{Kg} / \mathrm{h}$, onde as variáveis de processamento foram a rotação
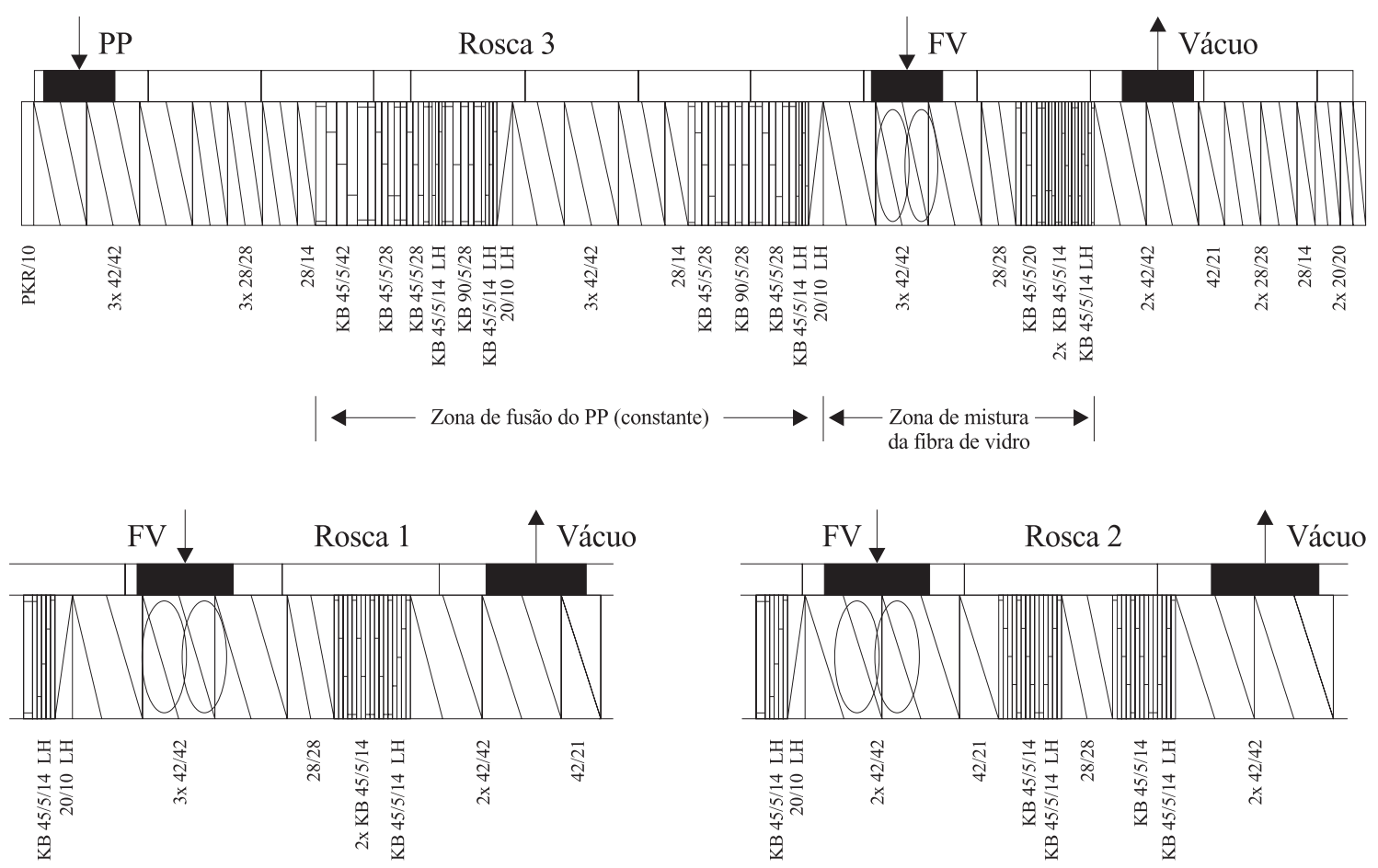

Figura 2. Três configurações de rosca utilizadas para preparação dos compósitos de PP/FV30 na extrusora dupla rosca ZSK-30, com grau de cisalhamento decrescente $(\mathrm{R} 3>\mathrm{R} 2>\mathrm{R} 1)$ na zona de mistura da FV. 
da rosca (100, 200 e 300 RPM), dois perfis de temperatura ao longo do barril da extrusora (180/190/220/ $\left.230 / 230 / 225{ }^{\circ} \mathrm{C}\right)$ e $\left(210 / 230 / 250 / 260 / 260 / 250{ }^{\circ} \mathrm{C}\right)$ com temperaturas na zona de incorporação/mistura da FV de $230{ }^{\circ} \mathrm{C}$ e $260{ }^{\circ} \mathrm{C}$ respectivamente. Foram utilizadas três configurações de rosca (R1, R2 e R3), onde se procurou variar a intensidade de cisalhamento do segmento dos blocos de malaxagem (kneading blocks - KB) na zona de mistura da FV, decrescente de $\mathrm{R}_{3}>\mathrm{R}_{2}>\mathrm{R}_{1}$, conforme apresentado na Figura 2.

Neste diagrama a primeira parte do perfil da rosca foi mantida constante nas 3 configurações da rosca para assegurar uma mesma história de cisalhamento/ plastificação do PP. Os três tipos de segmentos de malaxagem foram montados visando minimizar a quebra da FV, porém mantendo os requisitos necessários para boa mistura distributiva e dispersiva da FV, conforme estabelecido na introdução deste trabalho ${ }^{[2,6-8,11]}$.

Todos estes parâmetros materiais e variáveis de processamento combinados resultaram em 36 amostras extrudadas do compósito de PP/FV30. A amostra que apresentou a melhor combinação de resistência à tração e ao impacto, com a melhor distribuição de comprimento da $\mathrm{FV}$, foi designada como sendo a condição ótima de compostagem. Nesta condição otimizada, investigou-se então a influência do compatibilizante interfacial (PP-g-MAH) na quebra da FV, na adesão interfacial e nas propriedades mecânicas, em mais uma amostra de PP/FV30/PP-g-MAH5, substituindo 5\% em peso do PP homopolímero por PP funcionalizado.

Os corpos-de-prova (CP's) foram conformados, segundo as normas ASTM D638 (ensaio de tração - tipo I) e ASTM D256 (ensaio de impacto pendular Izod com CP's entalhados), numa injetora automática Arburg Allrounder 270V/300-120, com temperatura final do fundido em torno de $250^{\circ} \mathrm{C}$, molde à $70^{\circ} \mathrm{C}$, pressão de injeção de 450 bar e contra-pressão na rosca de 10 bar. Estas condições de moldagem por injeção foram mantidas constantes em todas as amostras e previamente otimizadas para minimizar a quebra da $\mathrm{FV}$ e obter CP's de boa qualidade.

A determinação da concentração da FV nas diversas amostras foi efetuada por perda ao fogo num forno de aquecimento por microondas, apresentando resultados próximos aos valores nominais, com uma variação de $\pm 1,8 \%$. As FV obtidas dessa queima, foram utilizadas na determinação da distribuição de comprimentos da FV em cada amostra por microscopia ótica com analisador de imagem (Quantimet 600). Uma contagem de 500-600 fibras foi utilizada para calcular os valores de tamanho médio numérico $\left(\mathrm{L}_{\mathrm{n}}\right)$ e volumétrico $\left(\mathrm{L}_{\mathrm{w}}\right)$ da fibra, tanto nas amostras extrudadas como nas injetadas, com as devidas dispersões e histogramas de distribuição de tamanhos. Os comprimentos médios numérico $\left(\mathrm{L}_{\mathrm{n}}=\Sigma \mathrm{l}_{\mathrm{i}} \cdot \mathrm{n}_{\mathrm{i}} / \Sigma \mathrm{l}_{\mathrm{i}}\right)$, volumétrico $\left(\mathrm{L}_{\mathrm{w}}=\Sigma 1_{\mathrm{i}}{ }^{2} \cdot \mathrm{n}_{\mathrm{i}} / \Sigma 1_{\mathrm{i}} \cdot \mathrm{n}_{\mathrm{i}}\right)$ e a dispersão entre eles dada por Disp $=\left(L_{w}-L_{n}\right) / L_{n}$, foram calculados e analisados, conforme exemplos apresentados na Figura 7.

Para verificar a influência da presença de FV na alteração do grau de cristalinidade da matriz de PP, foram realizadas análises de calorimetria diferencial de varredura (Perkin-Elmer, DSC-7, segundo a norma ASTM D3418-88) nos diversos compósitos de PP/ FV30, PP/FV30/PP-g-MAH5 e também em PP controle. As interações interfaciais polímero-reforço nos diversos compósitos de PP/FV30 foram verificadas qualitativamente por meio de análise de microscopia eletrônica de varredura (MEV) em superfícies de amostras crio-fraturadas de CP's de tração, submetidos a uma tensão prévia de $60 \%$ da sua resistência à tração.

\section{Resultados e Discussão}

\section{Influência de processamento na preservação da FV}

Inicialmente, verificou-se que o processo de compostagem na extrusora reduziu o comprimento médio da FV tal como recebida de $4,5 \mathrm{~mm}$ para uma faixa de 600 a $780 \mu \mathrm{m}$, sendo que as condições de processamento que forneceram maior grau de cisalhamento na zona de mistura/malaxagem da FV contribuíram para menores $L_{n}$ das $F V$ e vice-versa. O subsequente processo de moldagem por injeção reduziu ainda mais estes valores, passando para uma nova faixa de $L_{n}=410$ a $570 \mu \mathrm{m}$, sendo que os maiores valores obtidos corresponderam proporcionalmente aos compósitos com maior $\mathrm{L}_{\mathrm{n}}$ na extrusão. Os resultados da influência das variáveis de processamento no $\mathrm{L}_{\mathrm{n}}$ da $\mathrm{FV}$, estão apresentados na Figura 3 para todas as amostras extrudadas e injetadas de PP/FV30.

Analisando estes resultados para uma mesma temperatura de mistura $\left(230{ }^{\circ} \mathrm{C}\right.$ ou $\left.260^{\circ} \mathrm{C}\right)$ num mesmo tipo de matriz polimérica (PP3,5 ou PP20), verifica-se que existe uma tendência de redução do $\mathrm{L}_{\mathrm{n}}$ da $\mathrm{FV}$ com aumento de rotação da rosca e da intensidade de cisalhamento na zona de mistura da FV $\left(\mathrm{R}_{3}>\mathrm{R}_{2}>\mathrm{R}_{1}\right)$, sendo que esta redução do $L_{n}$ é mais acentuada quando 

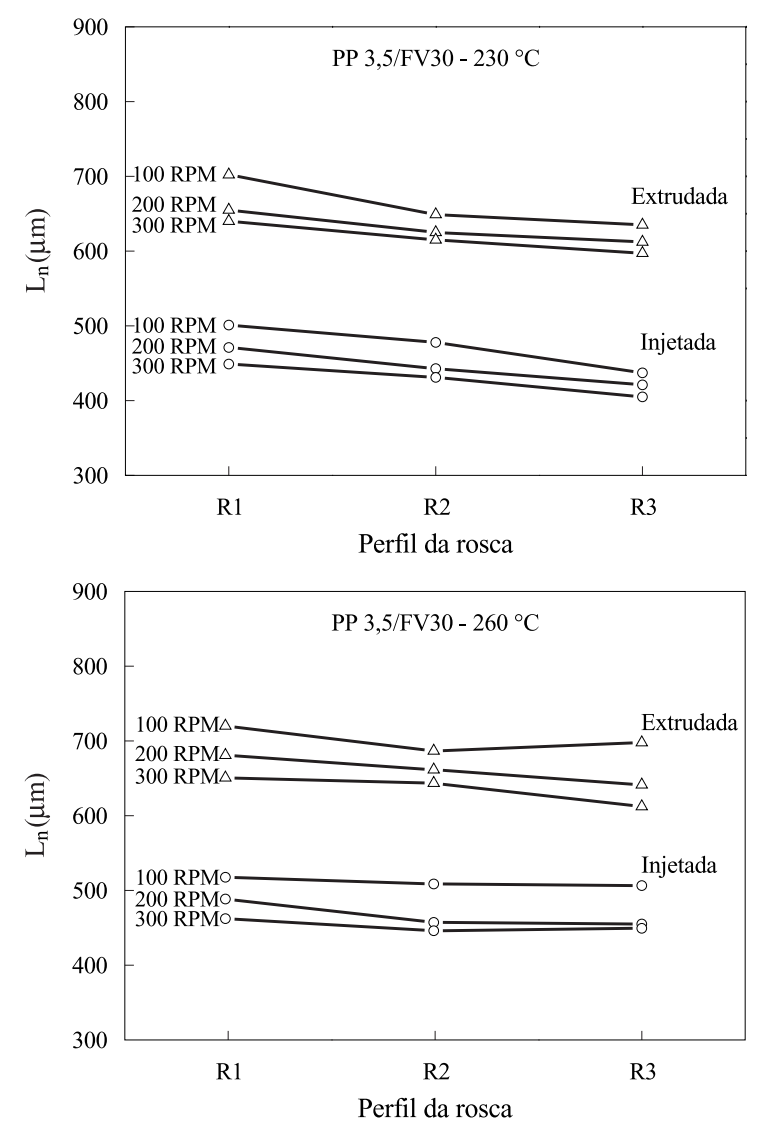
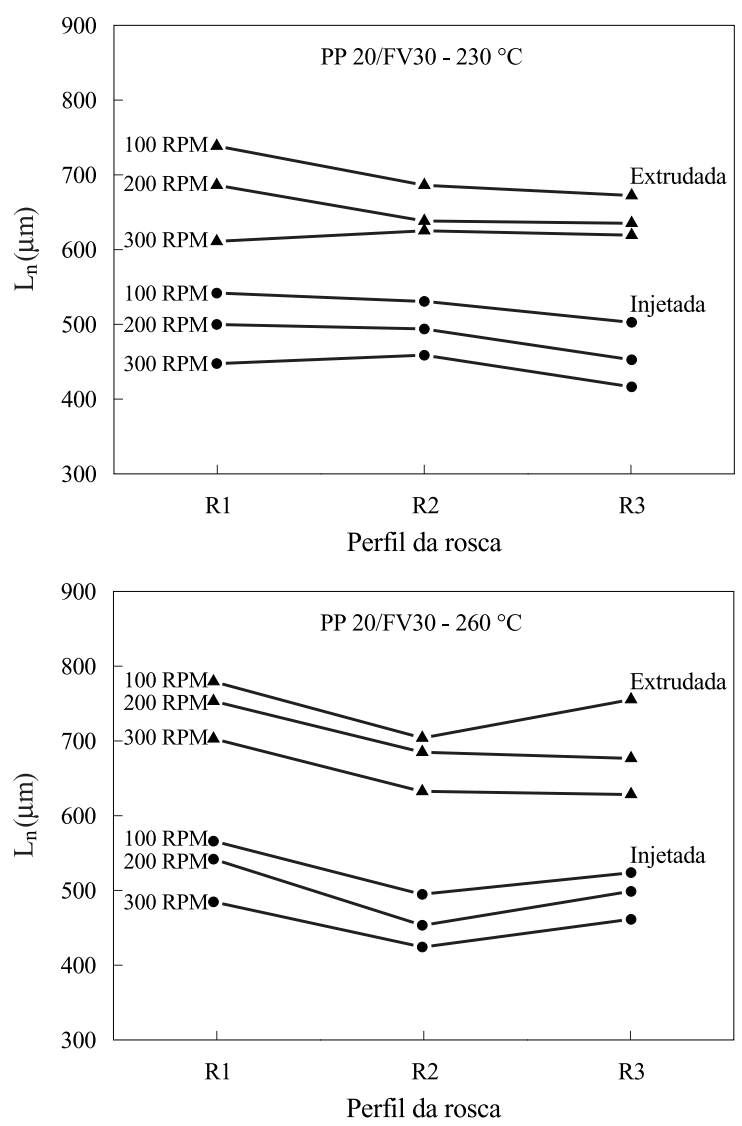

Figura 3. Influência das variáveis de processamento na quebra $\left(\mathrm{L}_{\mathrm{n}}\right)$ da FV para amostras dos compósitos de PP/FV30 extrudados (s) e injetados (1).

a combinação das condições de maior viscosidade do polímero (PP3,5), menor temperatura do fundido $\left(230^{\circ} \mathrm{C}\right)$ e maior rotação da rosca (300 RPM) contribuiu para maiores tensões de cisalhamento nas fibras ${ }^{[3-8]}$ $\mathrm{e}$, consequentemente, maior quebra da FV com o menor valor de $\mathrm{L}_{\mathrm{n}}=597 \mu \mathrm{m}$. Nas condições de processamento contrárias às acima citadas, obtemos a menor quebra da FV com o maior valor de $\mathrm{L}_{\mathrm{n}}=780$ $\mu \mathrm{m}$. Verificou-se também que a influência da rotação da rosca na quebra da $\mathrm{FV}$ foi maior que a da intensidade de cisalhamento da rosca. Entretanto, observou-se que a rosca $R_{3}$, apesar do seu perfil de cisalhamento ser o mais intenso das três roscas, preservou melhor o $\mathrm{L}_{\mathrm{n}}$ da FV que a rosca $\mathrm{R}_{2}$ nas condições de menor viscosidade (PP20) e de maior temperatura $\left(260{ }^{\circ} \mathrm{C}\right)$ na zona de mistura/malaxagem da extrusora.

\section{Influência de processamento na resistência à tração dos compósitos}

Os resultados da análise térmica por DSC dos compósitos de PP/FV apresentaram uma pequena variação no grau de cristalinidade da matriz de PP da ordem de 0,6 a $2,3 \%$, entre valores mínimo e máxi- mo, em relação ao PP controle. Consequentemente, pode-se inferir que as propriedades mecânicas destes compósitos não sofreram influência significativa da pequena alteração ocorrida na cristalinidade da matriz de PP com a presença da FV.

$\mathrm{Na}$ Figura 4 estão apresentados os dados de resistência à tração $\left(\sigma_{\text {máx. }}\right)$ em função da rotação da rosca para os compósitos de $\mathrm{PP} / \mathrm{FV} 30$, agrupados em 2 gráficos para cada temperatura $\left(230^{\circ}\right.$ e $\left.260^{\circ} \mathrm{C}\right)$ na zona de malaxagem da FV. Pode-se verificar aqui que para uma dada rosca $\left(\mathrm{R}_{1}, \mathrm{R}_{2}\right.$ ou $\left.\mathrm{R}_{3}\right)$ e determinado tipo de $\mathrm{PP}$, a $\sigma_{\text {máx. }}$ reduz com quebra da FV (valores de $\mathrm{L}_{\mathrm{n}}$ entre parênteses) em função do aumento de rotação da rosca, sendo que a queda de $\sigma_{\mathrm{m} \text { á }}$ é mais acentuada na temperatura de $230{ }^{\circ} \mathrm{C}$. Entretanto, analisando estes mesmos dados de $\sigma_{\mathrm{m} \text { á x }}$ para uma mesma rotação da rosca, verifica-se que não há uma correlação direta de $\sigma_{\text {má }}$ com $L_{n}$ da $F V$, já que esta propriedade depende tanto de $\mathrm{L}_{\mathrm{n}}$ da $\mathrm{FV}$ como do grau de adesão interfacial alcançado no compósito ${ }^{[3,6,9,14-17]}$. Portanto, para elucidar melhor as possíveis correlações entre $\sigma_{\mathrm{m} \text { á }}$ e as variáveis de processamento na extrusão, estes mesmos dados de $\sigma_{\mathrm{m} \text { á }}$ foram plotados em função do $\mathrm{L}_{\mathrm{n}}$ da FV, tal como apresentado na Figura 5. 

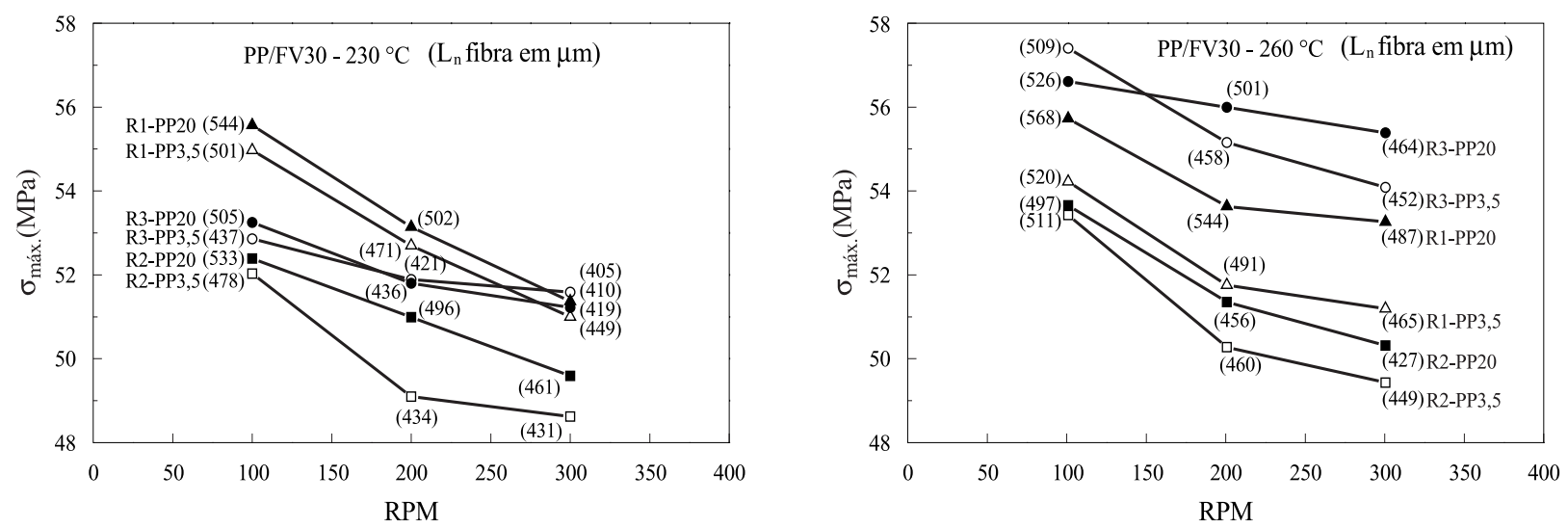

Figura 4. Resistência à tração $\left(\sigma_{\text {máx }}\right)$ dos diversos compósitos de PP/FV30 em função de rotação da rosca (RPM), nas temperaturas de $230^{\circ} \mathrm{C}$ e $260^{\circ} \mathrm{C}$ na zona de malaxagem da FV na extrusora.

Os quatro gráficos na Figura 5 foram elaborados para distinguir a influência da história de cisalhamento da extrusora na molhabilidade/adesão interfacial e na preservação do $\mathrm{L}_{\mathrm{n}}$ da $\mathrm{FV}$, em função das condições de processamento alteradas pela combinação da rotação e perfil de cisalhamento do segmento de malaxagem da rosca, e consequentemente, sua influência nas pro-
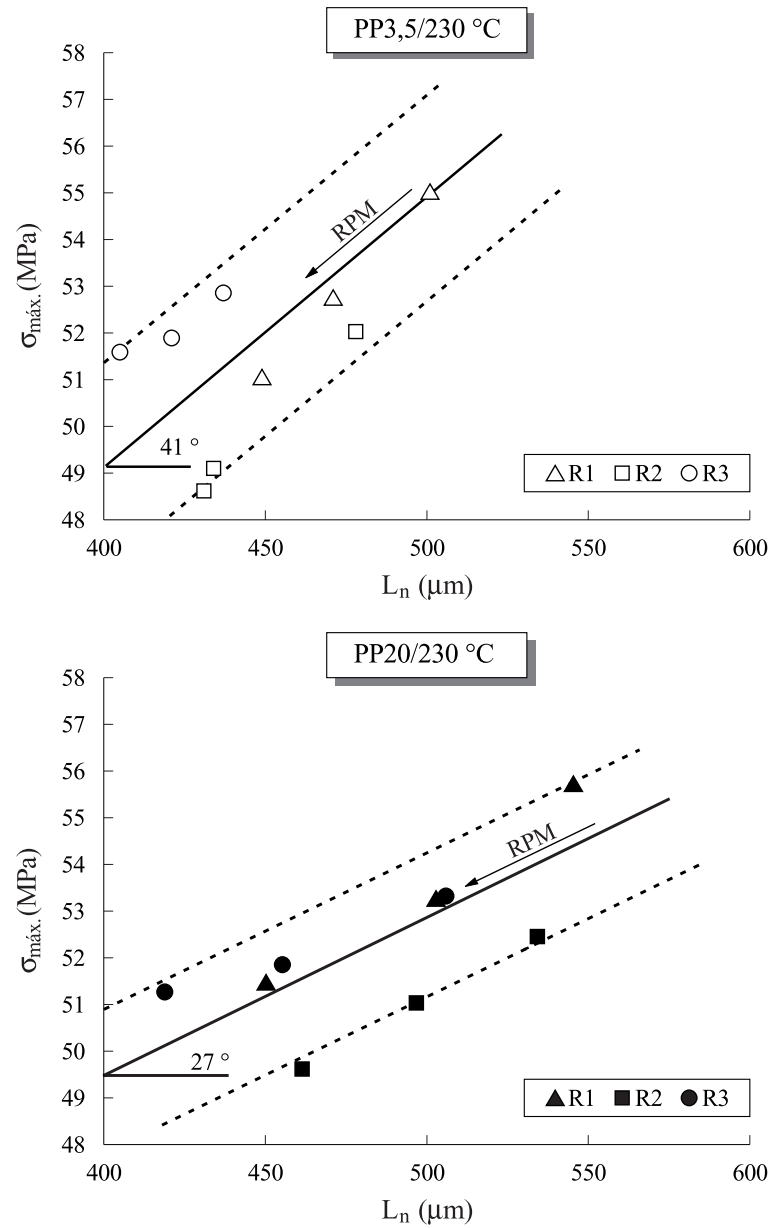

priedades de resistência à tração $\left(\sigma_{\mathrm{m} \text { áx }}\right)$ dos compósitos de PP/FV30. Neste caso, os dados de $\sigma_{\text {máx }}$ e $L_{n}$ dos compósitos nas 3 rotações e 3 configurações da rosca, para uma dada matriz de PP e dada temperatura de processamento, foram ajustados através de regressão linear com barras tracejadas do intervalo de ajuste. A inclinação da reta de ajuste indica que a correlação
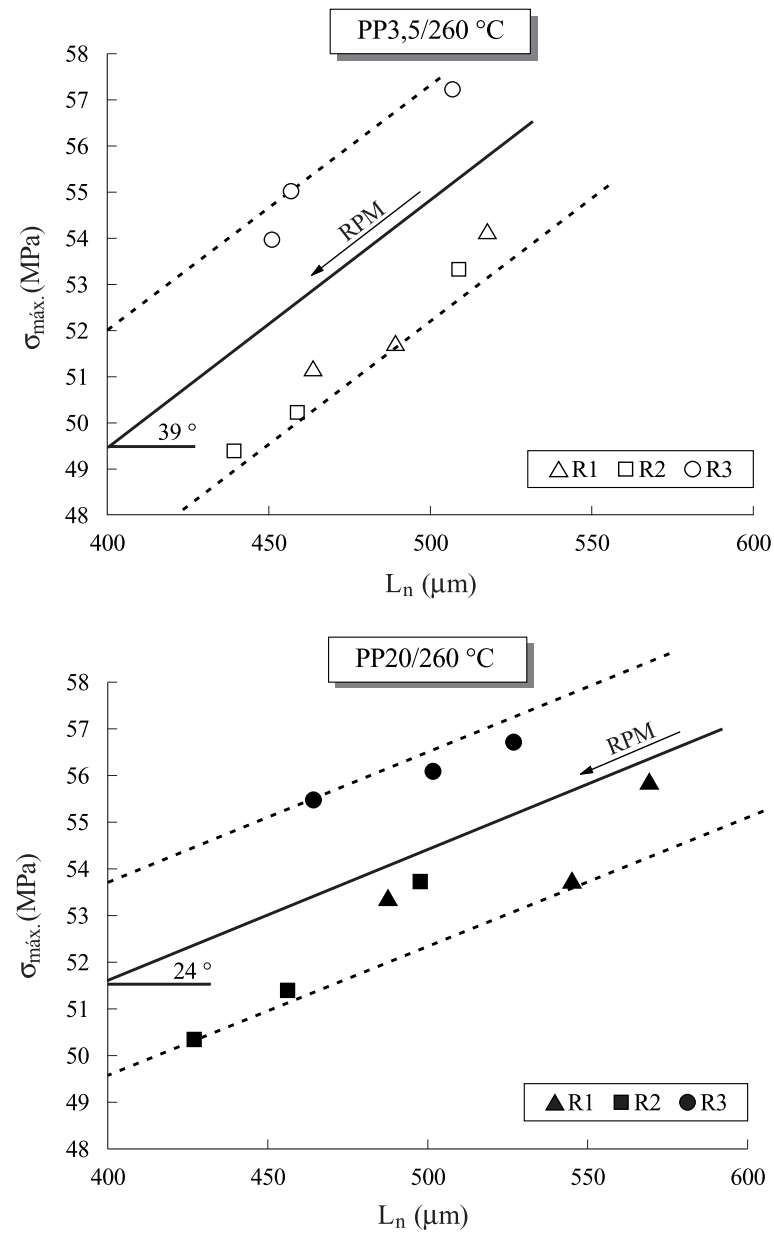

Figura 5. Resistência à tração $\left(\sigma_{\text {máx }}\right)$ em função do $\mathrm{L}_{\mathrm{n}}$ da $\mathrm{FV}$ para os compósitos de PP/FV30, com 2 tipos de matriz polimérica (PP3,5 e PP20) e nas temperaturas de 230 e $260{ }^{\circ} \mathrm{C}$ na zona de malaxagem da FV na extrusora. 
entre $\sigma_{\mathrm{m} \text { á }}$ do compósito e $\mathrm{L}_{\mathrm{c}}$ da $\mathrm{FV}$ é função do grau de adesão interfacial, segundo estipulado na equação 1 da introdução deste trabalho, propiciado pelo maior ou menor molhamento da FV com a variação na rotação da rosca. Analisando desta forma os 4 gráficos da Figura 5, verifica-se que os ângulos de inclinação das retas de ajuste são praticamente equivalentes para um mesmo tipo de PP, com uma pequena redução neste ângulo com aumento da temperatura de processamento. O compósito com maior viscosidade da matriz $(\mathrm{PP} 3,5)$ apresentou uma maior inclinação da reta de ajuste com média de $40^{\circ}$ em relação ao PP de menor viscosidade (PP20) com média de $25,5^{\circ}$. Isto significa que a dependência da $\sigma_{\text {máx }}$ em relação ao $L_{n}$ da $F V$ é maior nos compósitos com maior viscosidade da matriz, indicando que a redução no $\mathrm{L}_{\mathrm{n}}$ da $\mathrm{FV}$, com aumento da história de cisalhamento na extrusão destes compósitos, não é suficientemente compensada pela adesão interfacial alcançada nestas condições. Por outro lado, pode-se inferir que nos compósitos com menor viscosidade da matriz, esta mesma dependência foi substancialmente amenizada em função da maior molhabilidade e, consequentemente, superior adesão interfacial polímero-fibra alcançada nestes compósitos. Outra observação importante está relacionada com o desempenho da rosca $R_{3}$, que demonstrou ser a mais indicada para extrusão dos compósitos de PP/FV30 em função de sempre ter apresentado maiores valores de $\sigma_{\text {máx }}$ na temperatura de $260{ }^{\circ} \mathrm{C}$ nos 2 tipos de PP, indicando que a mesma otimizou os requisitos de molhabilidade e preservação de $\mathrm{L}_{\mathrm{n}}$ da $\mathrm{FV}$, apesar do seu perfil de cisalhamento mais intenso.

\section{Influência de processamento na resistência ao impacto dos compósitos}

Na Figura 6 estão apresentados os dados da resistência ao impacto Izod com entalhe (RI) em função do $\mathrm{L}_{\mathrm{n}}$ da FV para compósitos de PP/FV30. Como a RI de PP foi sensivelmente afetada pelo grau de degradação que a matriz polimérica sofreu em função da sua história de processamento na extrusão e injeção, tendo o PP3,5 virgem (controle) apresentado maior nível de perda nesta propriedade, buscamos então isolar a influência deste fator nos resultados de RI dos compósitos, apresentando-os em termos relativos (RI relativa) aos do PP controle submetido às mesmas condições de processamento na compostagem. Nesta figura, os dados de RI relativa e $\mathrm{L}_{\mathrm{n}}$ dos diversos compósitos de PP/FV30 nas 2 temperaturas de processamento, 3 rotações e 3 configurações da rosca foram agrupados em dois gráficos para cada uma das matrizes de PP utilizadas (PP3,5 e PP20) e ajustados através de uma regressão linear, similar à descrita na Figura 5.

Analisando de forma genérica os dados dos gráficos da Figura 6, verificamos que os compósitos de PP3,5/FV30 apresentam baixos valores relativos de RI (no intervalo de 1,4 a 2,0), enquanto nos compósitos de PP20/FV30 os valores relativos de RI estão numa faixa superior (1,9 a 2,5). Com exceção de apenas duas condições de processamento (com PP3,5 e na temperatura de $230{ }^{\circ} \mathrm{C}$ para roscas $R_{2} \mathrm{e}$ $\mathrm{R}_{3}$ ), aparentemente a RI relativa de todos os compósitos tende a aumentar com o $\mathrm{L}_{\mathrm{n}}$ da $\mathrm{FV}$, sendo que variação da RI relativa com a rotação da rosca é menor para os compósitos de PP3,5/FV30 (inclinação de $3^{\circ}$ na reta de ajuste) e maior nos compósitos de PP20/FV30 $\left(16^{\circ}\right)$. Para estabelecer as possíveis correlações entre a RI destes compósitos com as diversas condições de processamento em análise, é importante conhecer primeiro os diversos fatores materiais que influenciam as propriedades de tenacidade e RI de compósitos de TPRFVc.

A tenacidade à fratura (e RI) de compósitos de TPRFVc pode ser definida como sendo a energia absorvida ou dissipada durante a propagação de uma trinca. Esta energia advém do trabalho necessário para o desacoplamento/desmolhamento da interface fibra-matriz, deformação da interface e da matriz, e também do atrito no arrancamento da fibra embutida na matriz ${ }^{[12,16,27,28]}$. Segundo Suetsugu ${ }^{[12]}$, Gupta ${ }^{[16]}$ e Kim-Mai ${ }^{[27]}$, a RI do compósito aumenta com $L_{n}$ da FV em função da energia dissipada no trabalho de arrancamento das fibras (máximo quando $\mathrm{L}_{\mathrm{n}}=\mathrm{L}_{\mathrm{c}}$ ), e reduz com aumento na resistência ao cisalhamento interfacial, já que uma interface muito forte, comparada com a resistência coesiva da matriz, permite que as microtrincas se propaguem rapidamente através da matriz e das fibras, sem que ocorra desacoplamento interfacial e arrancamento das fibras e, consequentemente, o compósito apresenta baixa RI ou tenacidade à fratura. Por outro lado, uma interface muito fraca com $\mathrm{L}_{\mathrm{n}}<\mathrm{L}_{\mathrm{c}}$ também não é desejada, visto que neste caso não haverá significativa dissipação de energia no trabalho de desacoplamento interfacial, e consequentemente, nenhuma melhoria nas propriedades de impacto do compósito. Portanto, o trabalho de fratura só será maximizado com aumento de $\mathrm{L}_{\mathrm{n}} \mathrm{da}$ $\mathrm{FV}$, numa condição otimizada da resistência ao cisalhamento interfacial do compósito. 

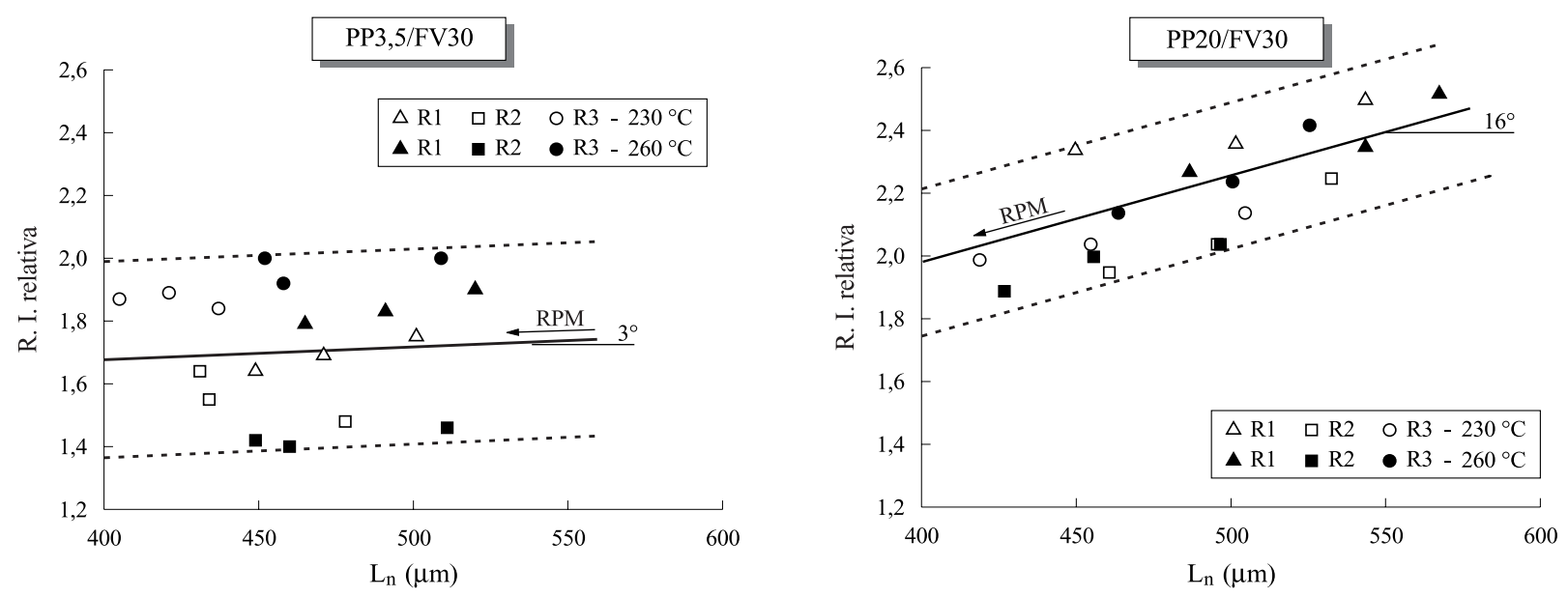

Figura 6. Resistência ao impacto Izod (RI) relativa em função do $\mathrm{L}_{\mathrm{n}}$ da FV para os compósitos de PP/FV30, com 2 tipos de matriz polimérica (PP3,5 e PP20) e nas temperaturas de 230 e $260^{\circ} \mathrm{C}$ de processamento da FV na extrusora.

Em função do acima estipulado, podemos inferir que a variação mais acentuada da RI relativa, à equivalentes incrementos de $\mathrm{L}_{\mathrm{n}}$ da FV, nos compósitos de PP20 em relação aos de PP3,5 (inclinação da reta de ajuste de $16^{\circ}$ contra $3^{\circ}$ respectivamente), é uma clara indicação de que a RI do compósito, além de ser uma função do $\mathrm{L}_{\mathrm{n}}$ da $\mathrm{FV}$, depende também de se assegurar uma adesão interfacial mínima nos compósitos. Entretanto, quando a viscosidade da matriz, nas diversas condições de processamento, não permite um molhamento adequado da FV e, consequentemente, não se atinge uma adesão interfacial mínima necessária, aumentos no $\mathrm{L}_{\mathrm{n}}$ da FV resultam em mínima ou quase nenhuma melhoria da RI relativa, conforme observado no gráfico da Figura 6 para todos os compósitos de PP3,5/FV30. Portanto, verificamos que a viscosidade menor da matriz de PP20, em comparação com a matriz de PP3,5 nas mesmas condições de temperatura de processamento, rotação e configuração da rosca, foi o fator de maior relevância a propiciar os maiores ganhos na RI relativa dos compósitos de PP20/FV30. Nestas condições, podemos inferir que as melhorias na preservação da FV e no grau de molhamento/ adesão interfacial fibra-polímero contribuem para maior dissipação da energia de fratura decorrente do trabalho de desacoplamento interfacial e de arrancamento das fibras da matriz. Esta observação contrasta com os resultados de Grillo et al. para compósitos de poliamida 6 com $\mathrm{FV}^{[17]}$, onde concluíram que a RI de TPRFVc é uma função predominantemente do $\mathrm{L}_{\mathrm{n}}$ da FV.

Outra observação importante verificada na Figura 6 está relacionada com o desempenho das 3 roscas utilizadas na preparação dos compósitos de PP20, onde a rosca $\mathrm{R}_{1}$ apresentou os maiores ganhos na RI relativa, nas mesmas condições de rotação da rosca $\mathrm{e}$ temperatura de processamento, enquanto a rosca $R_{3}$ teve um desempenho intermediário e a rosca $\mathrm{R}_{2}$ apresentou o pior desempenho das três.

Resumindo as principais observações sobre a influência das diversas condições de processamento e da viscosidade da matriz polimérica, em função dos pesos relativos atribuídos às mesmas, nas propriedades mecânicas dos compósitos de PP/FV30, podemos inferir que o melhor equilíbrio entre as resistências à tração $\left(\sigma_{\mathrm{m} \text { áx }}\right)$ e ao impacto (RI relativa) foi alcançado utilizando o polímero de menor viscosidade (PP20), na maior temperatura de processamento $\left(260^{\circ} \mathrm{C}\right)$, com o perfil de cisalhamento mais intenso da rosca na zona de mistura/malaxagem da FV $\left(R_{3}\right)$ e na rotação de 200 RPM da rosca de extrusão. Estas variáveis propiciaram a condição denominada "otimizada" de processamento na compostagem, e também verificou-se que o grau de importância destas variáveis nas propriedades mecânicas dos compósitos seguiu a mesma seqüência listada acima.

\section{Influência do compatibilizante interfacial nas propriedades mecânicas}

Na Figura 7 estão apresentados os histogramas de distribuição de comprimentos e valores médios de $\mathrm{L}_{\mathrm{n}}$ e $\mathrm{L}_{\mathrm{w}}$ da FV, e na Tabela 1 os resultados das propriedades mecânicas dos compósitos de PP20/FV30 e PP20/FV30/PP-g-MAH5, ambos processados na condição otimizada de compostagem na extrusora.

Analisando os dados de comprimentos médios da FV dos compósitos de PP20/FV30 com e sem 

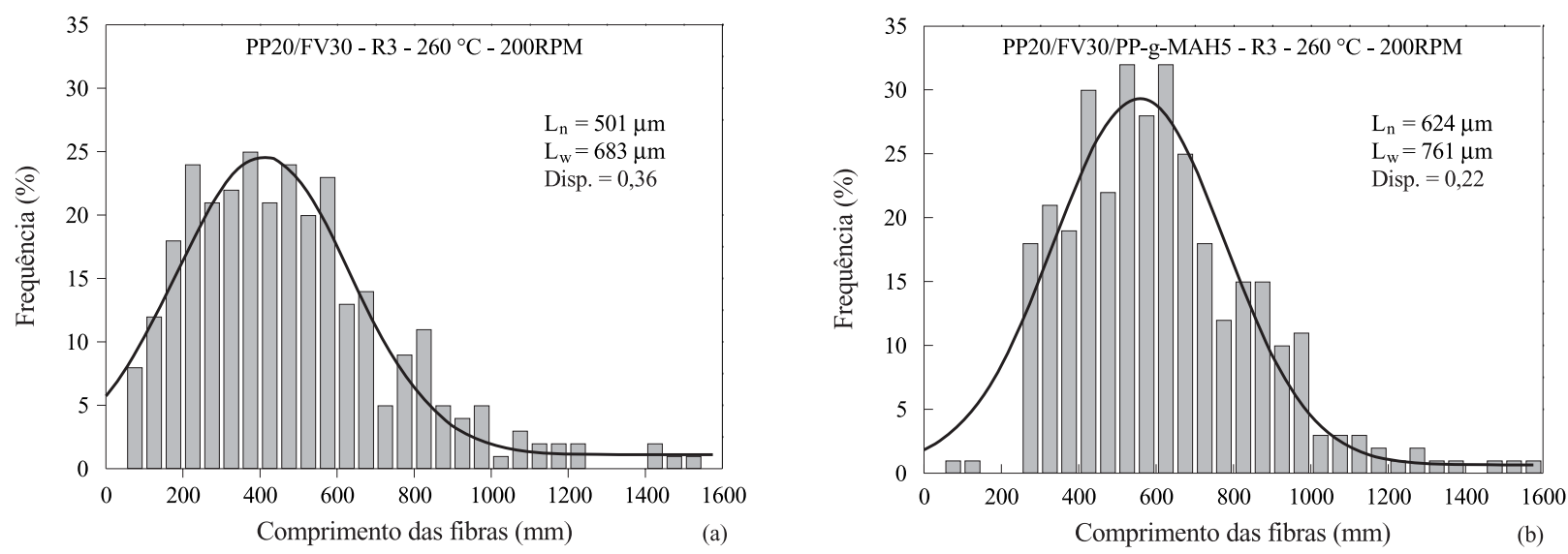

Figura 7. Histogramas de distribuição e valores médios dos comprimentos da FV em moldados por injeção para composições de PP20/30FV - (a) sem e (b) com 5\% de compatibilizante interfacial PP-g-MAH.

PP-g-MAH, verificamos que a presença do compatibilizante interfacial proporciona maiores valores de $\mathrm{L}_{\mathrm{n}}$ e $\mathrm{L}_{\mathrm{w}}$ da FV e uma distribuição mais estreita destes valores, indicando uma melhor mistura dispersiva e distributiva das fibras na matriz polimérica. Além disso, este comprimento médio da FV é superior ao maior valor de $\mathrm{L}_{\mathrm{n}}$ obtido nas melhores condições de processamento na extrusão anteriormente relatadas. Este mesmo efeito tem sido também constatado por alguns pesquisadores ${ }^{[10,17,18]}$, e pode ser atribuído à melhor preservação do comprimento da FV em função do maior grau de molhabilidade e mais eficiente encapsulamento das fibras pela matriz polimérica, advinda da redução na tensão interfacial fibrapolímero com a introdução dos grupos polares anidridos e carboxílicos do PP-g-MAH na matriz apolar de PP. Durante o processo de mistura da FV na matriz de PP, é assumido que os grupos co-reativos de ácidos dicarboxílicos do PP-g-MAH e os grupos básicos aminas do aminosilano reagem para formar um copolímero graftizado de PP-g-silano. Este copolímero está quimicamente acoplado à superfície da FV e fisicamente à matriz de PP através da interdifusão e emaranhamentos das cadeias poliméricas, atuando assim como compatibilizante na interface fibra-polímero e, portanto, melhorando substancialmente a adesão interfacial ${ }^{[19,20,23,26]}$.

Os dados apresentados na Tabela 1 sobre as propriedades mecânicas dos compósitos de PP20/FV30 com e sem PP-g-MAH, indicam claramente que a presença do compatibilizante interfacial propiciou ganhos substanciais nas propriedades de $\sigma_{\text {máx. }}(47 \%)$, RI $(51 \%)$ e deformação na ruptura $\left(\varepsilon_{\mathrm{r}}=89 \%\right)$, porém com redução no módulo de elasticidade (17\%) mesmo com aumento do $L_{n}$ da FV. Esta melhoria substancial na $\sigma_{\mathrm{m} \text { á }}$ pode ser atribuída aos aumentos no comprimento da FV e na adesão interfacial, conforme constatado em literatura atual sobre o tema ${ }^{[19-24,26]}$, enquanto a melhoria na RI poderia também ser atribuída ao aumento de $\mathrm{L}_{\mathrm{n}}$ da FV. Entretanto, nestas condições o aumento na $\sigma_{\mathrm{m} \text { áx }}$ com queda no módulo de elasticidade ou com ganho na $\varepsilon_{\mathrm{r}}$ são constatações aparentemente inconciliáveis dentro da teoria clássica de reforçamento de compósitos poliméricos com fibras de alto módulo e interfaces de monocamadas fortes e rígidas. Para explicar esta contradição, é necessário considerar a hipótese de que a interface do compósito de PP20/FV30/PP-g-MAH5 seja composta de uma camada interfacial (interfase do copolímero de PP-g-silano) com características de alta resistência ao cisalhamento, porém mais deformável. Nestas condições, como o módulo de elasticidade é medido à baixas deformações, a eficiência de transferência de tensão na interface é possivelmente diminuída em função desta interfase deformável e, consequentemente, o módulo do compósito será reduzido. Entretanto, se a resistência ao cisalhamento interfacial é elevada com a ação do compatibilizante interfacial, então tanto a $\sigma_{\mathrm{m} \text { á }}$ como

Tabela 1. Propriedades mecânicas dos compósitos de PP20/FV30 com e sem PP-g-MAH.

\begin{tabular}{lcccc}
\hline Formulação dos Compósitos & $\begin{array}{c}\text { R.T. }\left(\boldsymbol{\sigma}_{\text {máx }}\right) \\
(\mathbf{M P a})\end{array}$ & $\begin{array}{c}\text { Módulo de Elasticidade } \\
(\mathbf{G P a})\end{array}$ & $\begin{array}{c}\text { Alongamento na Ruptura } \\
(\boldsymbol{\%})\end{array}$ & $\begin{array}{c}\text { R.I. Izod } \\
(\mathbf{J} / \mathbf{m})\end{array}$ \\
\hline PP20/FV30 & $55,4 \pm 1,6$ & $4,1 \pm 0,2$ & $2,00 \pm 0,1$ & $68,1 \pm 2,5$ \\
PP20/FV30/PP-g-MAH5 & $81,5 \pm 0,5$ & $3,4 \pm 0,1$ & $3,78 \pm 0,2$ & $102,5 \pm 3,2$ \\
\hline
\end{tabular}




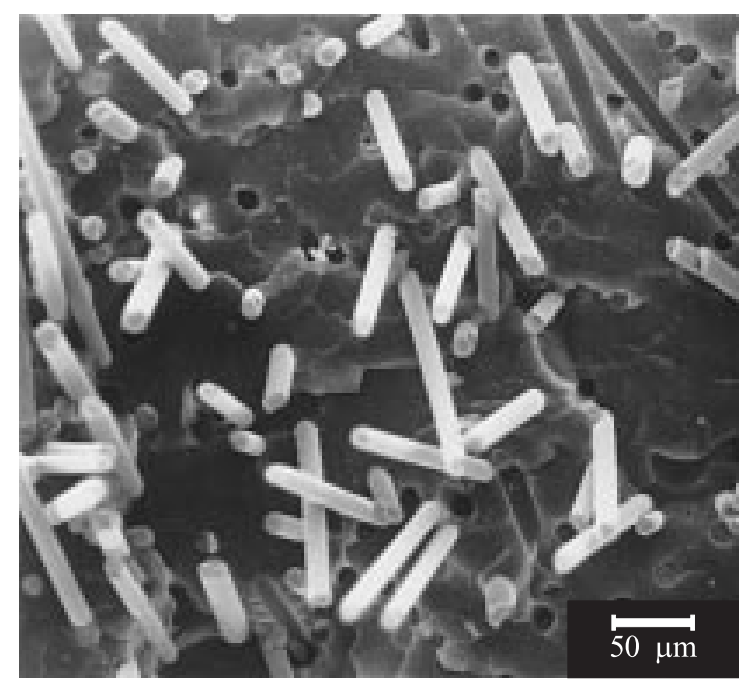

(a)

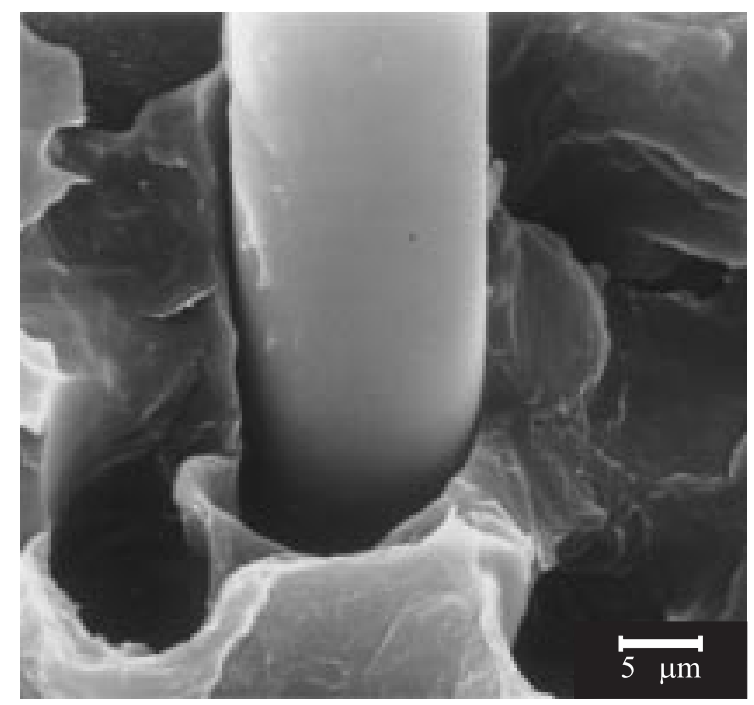

(c)

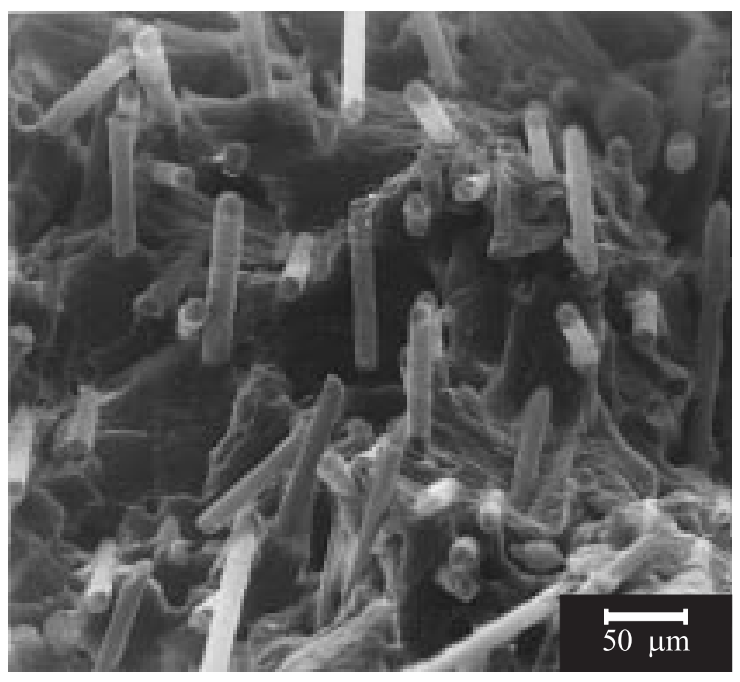

(b)

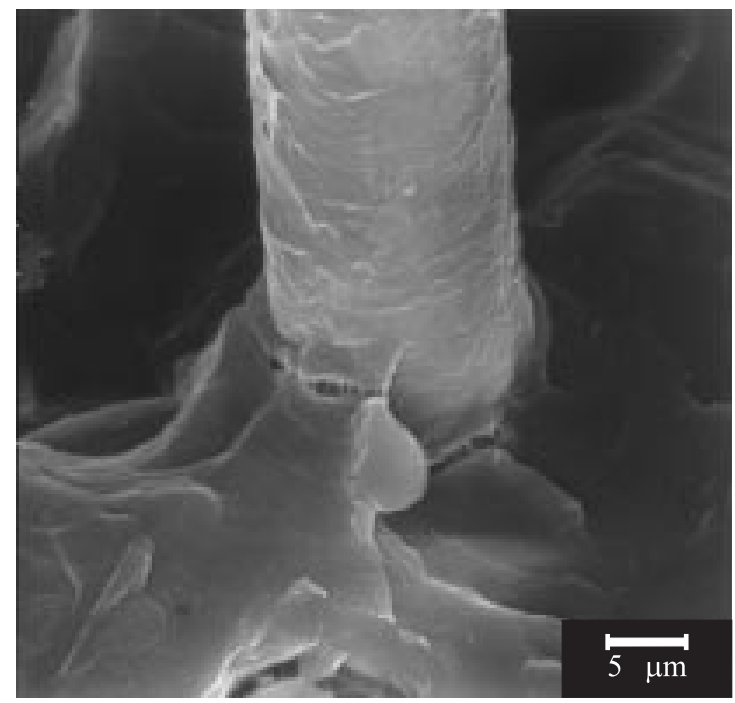

(d)

Figura 8. Fotomicrografias MEV de superfícies criofraturadas dos compósitos PP/FV30 sem (a \& c) e com compatibilizante interfacial (b \& d) em amostras submetidas a uma tensão prévia de $60 \%$ da sua resistência à tração.

$\varepsilon_{\mathrm{r}}$ deverão aumentar. A RI do compósito também aumentará nestas condições se maiores energias forem dissipadas no trabalho de deformação da interfase e da matriz na região próxima à esta interfase. Neste último caso, existe também a contribuição da maior energia dissipada no arrancamento das fibras de $\mathrm{L}_{\mathrm{n}}$ maior neste compósito. Dados sobre RI de compósitos de $\mathrm{PP} / \mathrm{FV}$ com uso de PP-g-MAH têm demonstrado que esta propriedade pode tanto aumentar ${ }^{[22,25,28]}$ como reduzir ${ }^{[18]}$, e acreditamos que estas diferenças advém provavelmente das características distintas da interface/ interfase formada em cada sistema.

Para corroborar as afirmações acima discutidas sobre o papel da interfase deformável nas propriedades mecânicas dos compósitos de PP/FV30 com compatibi- lizante interfacial, são apresentadas na Figura 8 as fotomicrografias da análise de MEV em superfícies criofraturadas de amostras submetidas a uma tensão prévia, com objetivo de analisar as características de adesão e deformação da região interfacial fibra-polímero. Analisando as fotomicrografias (8a) e (8b), verifica-se que a amostra sem compatibilizante interfacial apresenta vários vazios de arrancamento de fibras da matriz e nenhuma deformação plástica na sua superfície de fratura, enquanto na amostra com compatibilizante interfacial é verificada uma significativa deformação plástica da matriz e quase nenhum vazio de arrancamento de fibras. Nas fotomicrografias (8c) e (8d) é clara também a diferença na adesão interfacial, onde a presença do PP-g-MAH propiciou uma interface fibra-polímero 
mais coesiva. Estas duas verificações permitem inferir que existe uma interfase distinta de resistência ao cisalhamento interfacial superior, porém de características mais deformáveis, que justifica as propriedades mecânicas obtidas no compósito de PP20/FV30/PP-gMAH5. Atualmente estamos investigando a influência das características da interface/interfase nas propriedades mecânicas de curta e longa duração em compósitos de PP/FV, em função da combinação dos tipos de silano e compatibilizante interfacial empregados.

\section{Conclusões}

Levando em consideração que o principal objetivo deste trabalho foi investigar a influência conjunta das condições de processamento numa extrusora de rosca-dupla (perfil de temperatura, configuração e rotação da rosca), da viscosidade da matriz polimérica e das interações interfaciais fibra-polímero, na eficiência de reforçamento de compósitos de PP com 30\% em peso de FV tratada com aminosilano (PP/FV30) e com um compatibilizante interfacial (PP-g-MAH), chegamos as seguintes principais conclusões:

1. As condições que contribuíram para maior preservação do comprimento das fibras na extrusão foram aquelas que propiciaram a menor viscosidade da matriz (PP20) e maior temperatura de processamento $\left(260^{\circ} \mathrm{C}\right)$ na zona de mistura da FV, enquanto a influência da rotação da rosca na quebra da FV foi maior que a da intensidade de cisalhamento da rosca. O uso do compatibilizante interfacial foi o fator de maior predominância na preservação da $\mathrm{FV}$, com maiores valores de $\mathrm{L}_{\mathrm{n}}$ e $\mathrm{L}_{\mathrm{w}}$ e uma distribuição mais estreita.

2. A propriedade de resistência à tração $\left(\sigma_{\mathrm{máx}}\right)$ dos compósitos aumenta com o $\mathrm{L}_{\mathrm{n}}$ e com o grau de adesão na interface fibra-polímero, alcançados em função da preservação do comprimento da FV e do grau de molhamento propiciado pelas diversas condições de processamento. A inclinação da reta de ajuste entre os dados de $\sigma_{\mathrm{m} \text { a x }}$ e $\mathrm{L}_{\mathrm{n}}$ da FV é inversamente proporcional ao grau de adesão interfacial, propiciado pelo maior ou menor molhamento da FV com a variação na rotação da rosca. Baixos ângulos de inclinação das retas de ajuste indicam que a dependência da $\sigma_{\mathrm{m} \text { á }}$ com $\mathrm{L}_{\mathrm{n}}$ da FV é substancialmente reduzida em função da maior molhabilidade e, consequentemente, superior adesão interfacial fibra-polímero alcançada nos compósitos de menor viscosidade da matriz.
3. Foi verificado que a rosca $R_{3}$ demonstrou ser a mais apropriada para extrusão dos compósitos de $\mathrm{PP} / \mathrm{FV} 30$ por ter sempre apresentado os maiores valores de $\sigma_{\text {má }}$ na temperatura de $260^{\circ} \mathrm{C}$ nos 2 tipos de PP, indicando que esta rosca otimizou os requisitos de molhabilidade/adesão interfacial e preservação de $L_{n}$ da FV, apesar do seu perfil de cisalhamento mais intenso.

4. A resistência ao impacto (RI) relativa dos compósitos além de aumentar, essencialmente, com o $\mathrm{L}_{\mathrm{n}}$ da FV, depende também do grau de molhamento/adesão interfacial fibra-polímero se adequar à uma condição que permita maior dissipação da energia de fratura. Entretanto, quando a viscosidade da matriz não propicia um molhamento adequado da FV nas diversas condições de processamento, e a adesão interfacial não atinge um valor mínimo necessário, aumento no $L_{n}$ da FV resulta em mínima ou quase nenhuma melhoria da RI relativa do compósito.

5. A condição otimizada de processamento, que propiciou o melhor equilíbrio nas resistências à tração $\left(\sigma_{\mathrm{m} \text { á }}\right)$ e ao impacto (RI relativa) dos compósitos, foi alcançada utilizando o polímero de menor viscosidade (PP20), na maior temperatura de processamento $\left(260{ }^{\circ} \mathrm{C}\right)$, com o perfil de cisalhamento mais intenso da rosca na zona de mistu$\mathrm{ra} /$ malaxagem da FV $\left(\mathrm{R}_{3}\right)$ e na rotação de $200 \mathrm{RPM}$ da rosca de extrusão. O grau de importância destas variáveis nas propriedades mecânicas dos compósitos seguiu a mesma seqüência listada acima.

6. A presença do compatibilizante interfacial PP-g-MAH nos compósitos de PP20/FV30 propiciou ganhos substanciais nas propriedades de $\sigma_{\text {máx. }}$, RI e deformação na ruptura, porém com redução no módulo de elasticidade mesmo com aumento do $L_{n}$ da FV. Esta combinação de propriedades é atribuída à presença de uma interfase fibrapolímero com características de alta resistência ao cisalhamento interfacial, porém mais deformável. Estas características da interfase foram confirmadas através da análise de MEV em superfícies crio-fraturadas de amostras submetidas à uma tensão prévia.

\section{Agradecimentos}

Os autores agradecem o apoio financeiro da FINEP/PADCT-2, MCT/PRONEX, às empresas 
Polibrasil Polímeros S.A. e Cia. Vidraria Santa Marina - Div. VETROTEX e ao Centro de Pesquisas e Desenvolvimento da PETROBRAS (CENPES).

\section{Referências Bibliográficas}

1. Roberts, D.H.; Constable, R.C. \& Thiruvengada, S.Polym. Eng. \& Sci., 37, p. 1421-26 (1997).

2. Mack, M.H. - Plastics Eng., p. 33-35, April (1997).

3. Sekiya, T.; Nakamura, N.; Sugiyama M.; Hamada H.; Hamamoto A. \& Hiragushi M. - "Study on Interfacial and Mechanical Properties in Glass Fiber Reinforced Polypropylene Injection Moldings", in: "Design and Manufacturing of Composites", Proc. Joint Canada-Japan Workshop on Composites, Kyoto, p. 265-268, Aug. (1996).

4. Dospisil, D.; Kubát, J.; Plesek, M. \& Sáha, P. - Intern. Polym. Processing, IX (4), p. 303-309 (1994).

5. Chiu, W.Y.; Lu, H.C. \& Chang, C.L. - J. Appl. Polym. Sci., 43, p. 1335-41 (1991).

6. Nagae, S.; Nagura, K.; Yamagiwa, N.; Yamane, Y.; Miyage, K. \& Inoue, K. - Int. Polym. Proc., XII, p. 116-122 (1997).

7. Valsamis, L.N. \& Canedo, E.L. - Plastics Eng., April, p. 37-39 (1997).

8. Ramani, K.; Bank, D. \& Kraemer, N. - Polym. Composites, 16 (3), p. 258-66 (1995).

9. Maxwell, J. - Plastics and Rubber International, 8 (2), p. 45-50 (1983).

10. Tancrez, J.P.; Rietsch, F. \& Pabiot, J. - Eur. Polym. J., 30 (12) p. 1479-1487 (1994).

11. Andersen, P.G. - "Mixing Practice in Corotating Twin Screw Extruders", in: "Mixing and Compounding of Polymers: Theory and Practice", I. Manas-Zloczower \& Z. Tadmor (Eds.), Hanser, New York, p. 679-705 (1994).

12. Suetsugu, Y. - "The Effect of Mixing on Some Properties of Compounds and Composites", in: "Mixing and Compounding of Polymers: Theory and Practice", I. Manas-Zloczower \& Z. Tadmor (Eds.), Hanser, New York, p. 534-48 (1994).

13. Bigg, D.M. - Polym. Composites, 6 (1), p. 20-28 (1985).
14. Kelly, A. \& Tyson, W.R. - J. Mech. Phys. Solids, 13, p. 329-50 (1965).

15. Shortall, J.B. \& Pennington, D. - Plastics Rubber Proc. Appl., 2, p. 33-40 (1982).

16. Gupta, V.B.; Mittal, R.K. \& Sharma, P.K. - Polym. Composites, 10 (1), p. 16-27 (1989).

17. Grillo, J.; Papazoglou, E. \& Petrie, S. - "Effects of Polymer Viscoelasticity on Fiberglass Atrittion when Compounding Fiberglass Strand on the CoRotating Intermeshing Twin Screw Extruder", SPE ANTEC, Paper \#618, 9 pg. (1993).

18. Peltonen, P.; Pääkkönen, E.J.; Järvelã, P.K. \& Törmälä, P. - Plastics, Rubber \& Composites Processing \& Appl., 23, p. 111-126 (1995).

19. Karian, H.G. \& Wagner, H.R. - "Assessment of Interfacial Adhesion in Chemically Coupled Glass Fiber Reinforced Polypropylene", SPE ANTEC, p. 3449-55 (1993).

20. Mader, E.; Jacobasch, H.J.; Grundke, K. \& Gietzelt, T. - Composites Part A, 27A, p. 907-12 (1996).

21. Mader, E.; Jacobasch, H.J.; Grundke, K. \& Wachinger, G. - Composites, 25 (7), p. 739-44 (1994).

22. Mader, E. \& Frenzel, H. - Progr. Colloid Polym. Sci., 101, p. 199-202 (1996).

23. Rijsdijk, H.A.; Contant, M. \& Peijs, J.M. Composites Sci. Tech., 48, p. 161-72 (1993).

24. Thomason, J.L. \& Vlug, M.A. - Composites, Part A, 28A, p. 277-88 (1997).

25. Constable, R.C. - "Evaluation of Chemically Modified Polypropylene with Various Glass Fiber Types, for Performance Enhancement in Glass Filled Polypropylene", SPE ANTEC, 3 pg. (1993).

26. McLoughlin, K.M. \& Elliot, S.J. - "Properties of Glass-Filled Polypropylene, Nylon 6, and Polypropylene/Nylon 6 Alloys Compatibilized Using PP-g-MA”, SPE ANTEC, p. 1561-70 (1998).

27. Kim, J.K. \& Mai, Y.W. - Composites. Sci. Technol. 41, p. 333-78 (1991).

28. Thomason, J. L. \& Vlug, M.A. - Composites, Part A, 28A, p. 277-88 (1997).

Recebido: $15 / 01 / 99$ Aprovado:19/02/99 